\title{
The role of learned societies and grant-funding agencies in fostering a culture of open science *
}

\author{
Marc Brysbaert \\ Department of Experimental Psychology \\ Ghent University \\ Belgium
}

* To be published in Plonsky, L. (Ed.) (2022). Open Science in Applied Linguistics. John Benjamins. The present ms builds on Chapter 11 of Brysbaert \& Rastle (2020).

\author{
Marc Brysbaert \\ Department of Experimental Psychology \\ Ghent University \\ 9000 Ghent \\ Belgium \\ marc.brysbaert@ugent.be
}


In this chapter I discuss the roles learned societies and grant funding agencies can play in open science, building on their strengths and taking into account their weaknesses. A large part of the chapter is devoted to open access publications, where learned societies have a unique opportunity and responsibility. A smaller part is related to transparency in data collection, analysis and storage, where funding agencies have a strong say.

\section{Learned societies and the dissemination of research findings}

The first scientific journals were published by learned societies. According to the British Royal Society, their journal Philosophical Transactions was the world's first scientific journal, starting in 1665. At first, the articles were written reports of talks given to the society, without much editing. Gradually, quality checks, such as peer comments, were introduced (Baldwin, 2018). The proceedings published by learned societies were an alternative to the books and periodicals published by scientists themselves.

Learned societies have three major advantages when it comes to publish scientific journals. For a start, they have the knowledge to judge the quality of submissions. Learned societies are usually established by a group of researchers sharing a common interest. So, they have the best people to judge the quality of research on the topic. Second, learned societies are a better guarantee for continuation than individuals. Many journals are started and disappear after a few years. This is a concern for authors looking to announce their latest findings: How likely is it that the findings will still be available in 10, 20, 100, 1000 years' time? The desire for longevity is a stumbling block for starting journals but a benefit for established journals/societies. Finally, learned societies also give prestige to the journal. Authors want to publish their findings in prestigious journals. As always, part of the prestige is acquired (past performance of the journal), but part is derived (from the editorial board, the publisher and/or the learned society associated with the journal).

At the same time, learned societies have a weakness when it comes to publishing journals: They do not have the technical interest nor know-how to make accepted manuscripts available to the wider public. History is full of examples of amateurism in the scientific journals published by learned societies. The issues did not appear in time, manuscripts went astray, there were severe limits on the number of manuscripts that could be handled, and often there were considerable financial losses. This was because the publication was a side project of individuals primarily interested in research.

\section{0s-1990s: Commercial publishers relieve scientists from boring work}

Scientific research expanded rapidly in the $20^{\text {th }}$ century. Whereas yearly production was a few thousand publications at the beginning of the $20^{\text {th }}$ century, it was over three million in 2020. As demand rose, commercial publishers saw an opportunity for business. They proposed learned societies to relieve them from the menial work related to the existing publications or to start new journals for them. They also initiated new journals themselves when they found a group of researchers willing to form the first editorial board. This was possible because university libraries wanted to keep a full record of scientific output and had money to do so. 
At the same time, the publishers noticed that they could ask academics to do a lot of the work for free (editing and reviewing papers), as most academics were idealistic about their research and paid by universities. In addition, sales did not suffer much if prices were increased above inflation. Year-on-year increases of $10 \%$ or more in subscription fees were no exception. Around the same time, the production costs decreased because manuscripts were no longer submitted on paper, but digitally. This disposed of the postage costs and the costs of having to retype manuscripts for publication. The speed of the internet further made it possible to relocate much of the production and handling of manuscripts to counties with low wages.

By the beginning of the 21st century, scientific publishing was a vast industry with the highest profit margins within industry. For instance, in 2018 one of the largest publishers of scholarly journals, Elsevier, was estimated to have revenue of nearly 4 billion US dollars from 2600 scientific journals, of which more than 1 billion was profit.

The business model of commercial publishers critically depended (and still depends) on readers paying for access to the contents. The outcome of scientific research disappeared behind a pay wall. As long as university libraries were able to pick up the tab, most researchers did not notice. However, as more and more libraries were confronted with budget overdrafts, choices had to be made and researchers were faced with articles not available to them unless they were willing to pay a fee. The issue was most pressing at less wealthy universities but gradually became true at every university. Researchers were confronted with the pay wall not only as readers, but also as authors. Was it worthwhile submitting a manuscript to a journal not available at their own university (and at many other)? The same was true for learned societies: How large was the circulation of their journals and how could they optimize it?

\section{Societies differ in the choices and contracts they were able to make}

The negotiations between learned societies and commercial publishers mostly depend on choices and contracts made in the second half of the $20^{\text {th }}$ century. These differ between societies and some are more beneficial than other. I'll illustrate this with three learned societies I've been involved with.

\section{Society opts to remain an independent publisher}

The Psychonomic Society was established in the US in 1960, when a group of researchers was no longer satisfied with the conferences organized by the American Psychological Association (Dewsbury \& Bolles, 1995). One of the initiators had experience with scientific publishing and a desire to set up a publishing company (Dewsbury, 1996). As a result, the society became not only the publisher of its journals, but had its own printing company. Although there were some changes throughout the years, the society published a portfolio of six journals related to cognitive research, which had a good distribution in psychology libraries throughout the world. Things went well until the end of the $20^{\text {th }}$ century, when changes in publishing (digital storage and access) and library contracts (involving the competition of journal packages from big publishers) brought the publishing company to its knees and almost meant the bankruptcy of the society. Eventually, the society decided to close the publishing company and work with an established, commercial publisher (Springer). 


\section{Society keeps copyright of the journal}

The Experimental Psychological Society was established in the UK in 1946 (https://eps.ac.uk/). It rapidly started with its own journal, The Quarterly Journal of Experimental Psychology, which was printed by a local publisher in Cambridge. In 1969 publication passed to the American company Academic Press, which offered more international marketing. In 1984 the journal was transferred again to Lawrence Erlbaum Associates, and subsequently to Psychology Press, Taylor \& Francis, and Sage. Importantly, the society always kept the rights of the journal and negotiated with publishers for the best possible conditions. This allowed the society to make a substantial profit of the journal, which was used to organize conferences and award grants and prizes to members.

Society does not have copyright of the journal

The European Society for Cognitive Psychology was established in 1985 (https://www.escop.eu/). From its onset, the society wanted to publish a journal in addition to organizing conferences. British members with good contacts at Psychology Press (at that time the publisher of The Quarterly Journal) brought the society in contact with the publisher. The publisher was willing to circulate a journal for the society, if the society was able to provide an editorial board and to ensure a sufficient number of manuscripts. In case of exceptional performance, the society would get a small compensation, to be used for the workings of the society. In 1989, the European Journal of Cognitive Psychology launched its first issue. The rights of the journal (including the title, which changed to the Journal of Cognitive Psychology in 2011) stayed with the publisher and were transferred to Taylor \& Francis, when the company was sold to them. There were 5 -yearly contracts with the publisher, but these stayed within the constraints set by the publisher.

The arrangement became an issue when in 2017 the society wanted the journal to become open access. The publisher did not agree to the proposal, and eventually both parties ended the arrangement. The publisher kept the journal, for which it searched for a new editor, while the European Society started a new journal, The Journal of Cognition. By doing so, the society not only lost the history of its journal, but also inclusion in repositories such as the Web of Science and Scopus. These are important, because many universities and funding agencies make a decision between ranked journals and non-ranked journals, with the former having more weight. Ranked journals typically are journals included in the Web of Science or Scopus. So, having to start a new journal additionally implied that there were less incentives for researchers to submit manuscripts to the journal, until the society managed to get the journal included in the repositories (a process that typically takes 4-5 years).

\section{Open access journals}

As the prices of scientific journals increased and the costs for production decreased, a number of researchers (universities and learned societies) started to rebel. They reasoned that many of the impediments plaguing scholarly publishing in the past were no longer present. Manuscripts no longer had to be typed, libraries no longer had to be visited to sell subscriptions, and journals no longer had to be printed and shipped. Because of the internet, everyone could publish a text file and make it available to the entire world, certainly after the World Wide Web standard was released in 1991. 
The first campaigners were idealistic individuals and research groups with IT-skills. They resented the slow, effortful and expensive communication channels provided by journals, and set up their own communication channels, sometimes related to regular meetings and conferences.

Crawford (2002) made a study of the open access pioneers. He studied 86 journals listed in a librarians' directory of 1995. He was particularly interested in whether these journals survived in the subsequent six years. Indeed, a concern about informal journals is that they flourish for a few years but then languish as the initial enthusiasm and idealism of the creators declines, a problem all too familiar with the noncommercial scholarly publications of learned societies.

Of the 86 electronic journals, Crawford found that 49 survived six years (57\%), half of them with a small but steady flow of manuscripts, and half with substantial numbers of refereed articles. When Brysbaert and Rastle (2020) rechecked Crawford's list, 34 of the 49 journals were still running, although one had changed to a subscription journal with a commercial publisher.

Laakso et al. (2011) documented the open access publishing till 2009. In that period of time, the number of open access journals increased at a faster rate than the number of journals in total. Laakso et al. estimated that in 2009 the share of articles in open access journals was $7.7 \%$. At the end of 2019 , the Directory of Open Access Journals (https://doaj.org/) tracked 14 thousand open access journals with 4.5 million articles in total. A list of open-access journals in language research is maintained by Al-Hoorie at https://www.ali-alhoorie.com/applied-linguistics-open-access-journals, covering 166 journals in 2021. A prominent example has been the creation of Glossa: A journal of general linguistics in 2016, after the editorial board of a leading journal published by Elsevier resigned to protest against their inability to come to an agreement about fair pricing models for open access publishing (Rooryck, 2016).

Because of the costs involved in managing open access journals, most open access journals are compelled to ask an article processing charge (APC) from their authors. That is, the authors have to pay a charge to make their article available. In return, the journal promises that the article will remain freely available for everybody in the foreseeable future. A feature of subscription journals is that readers have to pay to get access to the contents. The articles are behind a pay wall, which in practice means that only researchers at (wealthy) universities can read them. Open access journals wanted to change this practice and stressed the importance of free and universal access to knowledge. Rather than making money out of readers, researchers were asked to pay for the costs of making the information available and maintaining it. Ideally, researchers could pay with money saved because journal subscriptions would no longer be needed. Instead of paying subscription fees to commercial publishing companies, the money would be used to make information freely available to everyone.

\section{Open access journals are not immune to commercial gain}

Arguably, scientists have repeated their publication mistake by supporting non-academic open access companies. In this way, they invested in the creation of companies that were more interested in increasing their costs and profits than in making scientific findings freely available. This became clear in the rapid rise of article processing charges. Whereas one thousand dollars was a typical charge in the early years, by 2020 two thousand dollars was becoming a minimum. 
Companies said the rise was unavoidable because the model was not sustainable otherwise. For instance, the company behind one of the main open access journals, Plos One, reported a substantial operational loss in 2019 and argued for a further increase in APC. At first sight, this looks like a genuine problem, because the company is a so-called not-for-profit organization that is not trying to make money for shareholders. However, the company seems to have many costs that do not agree with the open science movement. For example, its headquarters are in one of the most expensive parts of the world (San Francisco) and it has a large management board that is paid very handsomely (much more than researchers, not to mention editors and reviewers). The same is true for other commercial open-access publishers: Their APCs are rapidly increasing to a level that risks making publication as expensive (and profitable) as the old scheme.

The fact that open access journals became moneymaking can also be seen in the journals set up by established publishers. One of the most spectacular is the mega-journal Scientific Reports, published by one of the big commercial publishers (Springer). Mega-journals are large-volume, peer-reviewed, open access journals designed to make more scientific findings available by focusing on methodological rigor rather than theoretical contribution. They usually have a large remit, so that articles on many topics can be included. Scientific Reports started in 2011, when it published 205 items. In 2016 it overtook Plos One as the largest scientific journal in the world, publishing 21 thousand items. In 2020 it published over 22 thousand items. APC in that year was $\$ 1,990+V A T$, resulting in a VAT-free income of over $\$ 40$ million.

In several countries established publishers also managed to convince authorities/researchers that the best way to combine the ideals of open science with the realities of the publishing industry was to pay for open access in existing subscription journals. By paying an additional fee (often larger than the one asked by fully open access journals), authors could buy free access to their articles. This was called the hybrid model by the publishers, and double dipping by critics (because publishers managed to secure an extra income in addition to journal subscription).

Finally, the open access movement also gave rise to so-called predatory journals. These are journals that give the impression of being genuine (peer-reviewed, with mechanisms of error control, promise of longevity) without adhering to the standards they promise. They try to lure scientists to pay APCs for very limited services.

An example of the services given by predatory journals is provided by McKay and Coltheart (2017). The authors started with the observation that it had become common for academics to receive invitations from unfamiliar sources to attend conferences, submit papers, and join editorial boards. To push the test to the limits, they "wrote" a one-page manuscript with an algorithm that generated syntactically correct but surreal sentences. The first few sentences of the manuscript seemed relevant to the title but the paper then quickly deteriorated into a sequence of gibberish sentences. The title of the paper was "Addictive impairment in Pratiques de publication: A surrealist analysis". The first paragraph started with the sentences: "One of the aims of cognitive neuropsychiatry is to develop a model of the processes underlying normal belief generation and decision-making, and to explain addictive disorders in terms of impairments to processes implicated in this model of normal functioning. Cognitive neuropsychiatry can be viewed, in this sense, as a branch of cognitive neuropsychology, a field that investigates disordered cognition as a means of learning more about normal cognition." However, then it continued as follows: "Of course, neither cognitive neuropsychiatry nor cognitive neuropsychology is remotely informative when it comes to breaking the ice with buxom grapefruits. When pondering three-in-a-bed romps with 
broken mules, therefore, one must refrain, at all costs, from driving a manic-depressive lemon-squeezer through ham." The gibberish continued up to the end, including an acknowledgment that read as follows: "This research was supported by the Flattened Hedgehog Foundation (FHF) grant no. 62247. Thanks to Raven Black for helpful suggestions."

McKay and Coltheart (2017) submitted the "paper" to the ten journals that contacted either of them on the days between 21 June and 1 July 2017 and invited them to submit a paper. After receiving the manuscript, all ten journals responded and informed the authors that their manuscript was sent out for review (even though it was rubbish and should have been desk-rejected by the editor). McKay and Coltheart did not hear anything further from four publishers, arguably because they saw the problem. Of the others, two tentatively accepted the paper pending minor revision and four fully accepted it for publication pending APC payment. Importantly, some of the journals were associated with established scientific publishers. Needless to say, this is reducing 'scientific' publications to paid-for outlets without any quality assurance.

\section{Learned societies are the best guarantee for the ideal of open access publications}

For the reasons outlined above, I have come to the conclusion that learned societies are the best (only?) guarantee we have to make open access publications work. Their strengths remain the same as for regular journals: Learned societies bring knowledge, continuity and prestige to an open access journal.

Learned societies are better than commercial companies, because financial gain and exuberant management pay are not their main aim. This being said, learned societies are not immune to financial incentives either. Several societies have managed to generate a good income from their journals, which is used for the workings of the society and for supporting members in need. These societies have considerable income to lose if they make their existing journals open access or if they start new open access journals that may cannibalize their existing journals. In my experience, vested interests are a particular concern for English-speaking countries (mostly the USA and the UK). It is probably not a coincidence that the open access movement has had more dynamism in non-English speaking countries, where there are fewer vested interests (and possibly a desire to reduce the Anglo-Saxon hegemony).

Finally, it is possible to limit the risks related to the fact that learned societies lack the skills/interest to make articles easily available to readers. A number of new publishing companies have been established (sometimes by idealistic ex-researchers), that offer open access services at reasonable prices. If a learned society is smart enough to keep the journal rights, it is possible to set up fruitful collaborations with these companies. By making contracts limited in time and renewable, problems in the collaboration can be addressed.

\section{Some considerations for setting up an open access journal}

Setting up an open journal is not so much different from setting up any other business. In particular, you need a realistic business plan and clear ideas about what you want to achieve. For a start, it is good to think of how many submissions you are likely to receive and how many articles you expect to publish. Some learned societies want to be idealistic and make free publication possible. Usually, this works as 
long as the journal remains small. However, if the journal must be able to offer an outlet for hundreds of researchers, you need a plan that will not ruin the society. This is where APCs (author processing costs) come in.

Another consideration is whether you want to go for a low-cost shop in a back alley or a shop in the high street. It is possible to reduce costs by opting for the cheapest solutions, but these come at a price. The two most important elements to take into account are the user-friendliness of the journal submission system and the visibility of the journal to researchers outside the learned society. As for the submission portal, you can go for a cheap but unknown system, which is likely to provoke quite some frustration in authors and reviewers, or you can pay for a familiar portal. The latter costs more per manuscript the fewer manuscripts you receive. A similar logic applies to the visibility of the journal outside the learned society. If you are with a dynamic, established publishing company, it will be easier to get the journal listed in the necessary repositories, which will increase the visibility of the contents (and their status). Another example of the choices you have to make, is the degree of editorial help you want in turning accepted manuscripts into published articles. You can do this all yourself (as long as the number of articles is small) or you can pay for such services.

All in all, I've come to believe that it is reasonable to expect a cost of $\$ 1,000$ for the publication of a good, open access journal article. This includes (among other things):

- $\quad$ Having a submission portal to which authors can submit manuscripts and which is easy to use for reviewers and editors.

- $\quad$ Having accepted manuscripts checked for language and other errors (in particular the reference list).

- $\quad$ Standardizing the lay-out of accepted manuscripts.

- $\quad$ Paying VAT (i.e., sales tax) for the articles you publish.

- $\quad$ Having a stable server on which the journal is hosted (plus guarantees that the information remains available if you change publisher).

- Making sure that the journal contents are covered by all relevant archives and search databases, so that the contents can be found.

- $\quad$ Effort required to get an impact factor for the journal.

- $\quad$ Building up some reserve for fee waivers and unforeseen costs.

APCs can often be covered with grant money, but they are an obstacle for young researchers on cheap and precarious contracts (which unfortunately seem to be on the rise at many universities). This is an opportunity where learned societies can step in, by keeping money available for fee waivers. Funds can be kept aside at institutions and departments as well. In all cases it is good to observe transparent award rules (with an independent committee including representatives of young researchers), not to increase the power of those deciding about the money.

\section{Alternative solutions}

Societies may have good reasons not to start an open access journal (mostly vested interests). However, this does not preclude them to think of ways in which they can promote free access to scientific findings. An interesting example is the Psychonomic Society, discussed above. After they stopped their own publishing company, they negotiated an interesting contract with Springer. One of the elements they 
managed to negotiate was that journal articles became permanently open access after one year. This resulted in less income for the society but was considered to be a good compromise to combine free access to research and the workings of the society. The arrangement was prolonged in the renegotiation. So, societies with a clear vision can be creative in finding acceptable solutions, as long as they keep the rights on their journals.

Another alternative might be for societies to think bigger. Publishing costs per article diminish the more articles are processed and published. Having more than one journal increases the negotiation power of the learned society. At some point, it might even be considered whether it is an option to have production inside, with an own publishing house. If the latter option is considered, it is important to keep in mind, however, that it means the society will have a commercial arm that needs expertise, continuity, and innovation (in a changing world) for good functioning. My impression is that such interests are not the core strengths of learned societies and that time-limited contracts with specialized publishers give better value for money, but l'll be happy to be proven wrong.

\section{The contribution of grant funding agencies}

Attentive readers will have noticed that so far I remained silent about the role of grant funding agencies in open science. This is because I do not believe funding agencies have a big role to play in open access publications. Funding agencies are the quality guarantors for funding good research, but are not (and should not be) involved in publishing the results. So, they have few means to influence the process. Their main weapon is to make research funding conditional upon open access publication. In terms of stick and carrot, this clearly is the stick side. By using threat of punishment, they constrain researchers without giving a useful alternative. Ironically, this usually results in continuing and exacerbating existing practices. Whenever funding agencies negotiate with authorities, publishers, universities and learned societies, they end up paying for publication in existing journals (and thereby taking away money that could have been spent on research). This is because, when pressed, they have little else to offer. So far, this has led to hybrid publishing (paying for - expensive - open access in subscription journals) and to financial arrangements between universities/countries and publishers, so that members of the universities/countries can publish open access for free. Needless to say, these arrangements decrease the choices in the system and increase the power of the existing (big) players.

The only examples I have seen of helpful publication initiatives by funding agencies are those in which they teamed up with learned societies and provided money to start a new journal. The journal Glossa (discussed above) is a good example. When the editorial board decided to set up a new, open access journal, they too were confronted with losing access to Web of Science and Scopus. In order to bridge the time of non-inclusion, the editorial board was able to secure money from research councils (mostly from the Netherlands), so that they could waive APCs in the first 5 years. This largely contributed to the success of the journal.

Funding agencies can also include open access fees in the grants and fellowships they award. It is good to keep in mind, however, that this is a double-edged sword. If funding agencies give generous allowances for free publication, the first ones to capitalize on it will be commercial publishers, as there will be more money in the system that can be syphoned off. Again, I see little alternative to a collaboration with frugal learned societies if the system is to stay on track for more than a few years. 
The limited part in open access publication does not prevent funding agencies from playing an important role in the open science movement. They have their own strengths that make them powerful players. Apart from having money, their main muscle is being able to set the conditions for good research. Indeed, open science is much more than free access publication. It also involves setting the conditions of what characterizes good researchers, and how data must be gathered, analyzed and made available to other researchers (Klein et al., 2018; Munafo et al., 2017). Below I give some examples of how funding agencies can contribute to these aspects (see also Van Calster et al., 2021).

\section{Good research is not the same as publishing in high-impact journals}

One of the reasons why pay-walled publications have determined the lives of researchers so strongly is that scientists became judged on the number of papers they managed to publish in journals with a high impact factor according to commercial firms (primarily Web of Science and Scopus). The impact factor refers to the number of citations journal articles manage to attract after publication: Articles not referred to by other researchers can hardly claim to have made much difference in the accumulation of knowledge. The rise of the journal impact criterion made sense for some time to distinguish strong from weak scientific publications, but by now the criterion has more weaknesses than advantages. The weaknesses are (among others):

Journal impact factors give misleading information. Journal impact factors do not inform funding agencies about the impact of the individual paper entered by the applicant. They are the average number of citations to an article in the journal. Many articles in high impact journals score low on impact (i.e., have few citations in the first years after publications), whereas some articles in low impact journals score high (i.e., are cited a lot after publication). In addition, journal impact factors with a precision of three digits give misleading information, because the precision is artificial and averages are only meaningful for symmetric distributions. If a journal impact factor is to be calculated, it should be based on the median number of citations and have one or at most two digits of precision (depending on the size of the category the journal is in). If this definition is used, very few differences remain between journals, however.

- $\quad$ Reliance on journal impact factors devalues contributions not published in journals. These include publications in books, but also technical and methodological contributions that are rarely considered publishable by existing journals.

- $\quad$ Reliance on journal impact factors devalues research not published in English and on topics of less interest to speakers of English.

- Journal impact factors encourage editors to publish sensational, risky findings that are likely to stir much interest (but may not be replicable).

Journal impact factors make the firms calculating them too powerful. They have some lenience on which variables to use in the calculation and, more importantly, which journals to include in their lists (as we have seen, it takes years before new journals are taken on board).

The first learned society to openly criticize the use of journal impact factors as criterion for research quality was the American Society for Cell Biology in their Declaration on Research Assessment (DORA), published in 2012. The declaration asked science funders and evaluators to look at the quality of the research itself (proposed and completed) rather than at the prestige of the outlets in which the research was published. It argued that the outputs from scientific research are varied, and that they need to be 
evaluated wisely. It then discussed the problems with journal impact factors and offered a number of recommendations aimed at funding agencies, academic institutions, journals, organizations that supplied metrics, and individual researchers. The following themes ran through the recommendations:

Research output must be evaluated on its own merits rather than on the basis of the journal in which the research is published.

- $\quad$ Outputs other than journal articles are important in assessing research effectiveness and will grow in importance in the future, given the opportunities provided by online publication and data use.

- $\quad$ The use of journal-based metrics, such as journal impact factors, must be eliminated in funding, appointment, and promotion considerations.

DORA encouraged funding agencies to be explicit about the criteria they use for decisions, clearly highlighting that the scientific content of a paper is much more important than publication metrics or the identity of the journal in which it was published. This is particularly important for early-stage investigators, whose individual impact may not yet be visible in their track records. A funding agency blinded by impact factors of existing (commercial) journals is one of the surest impediments against open science efforts. The same is true for hiring and promotion committees. This requires that the committee is able to evaluate the quality of the research done by the candidates. To some extent, assessors can profit from the availability of Google Scholar, which allows them to track the short-term impact of papers and in outlets other than established journals. Of course, this is a criterion that can (and will) be gamed as well (e.g., via publicity in social media), so that it should not be the only decision criterion either.

\section{Rewarding open science initiatives}

Another way in which funding agencies can promote open science is by increasing funding chances of applications that follow open science practices. Open access publication is but one aspect of open science. Equally important are transparency in data collection, data analysis and data availability (for reanalysis and secondary analysis). Grant applications that include these elements can be given higher funding priority, because they help robust, cumulative science. All too often, data gathered as part of a research project disappear at the end of the project and are very hard (often impossible) to retrieve for new analyses or as the basis for further research (Vines et al., 2014).

Similarly, if funding agencies value theoretical, hypothesis driven research, they can give priority to applications working with preregistration. In such a system, researchers publicly announce their plans to run and analyze a hypothesis test, before the data are collected. Preregistration is particularly relevant when researchers test their own theory (see Huensch, this volume). In such cases, funding agencies may want to make sure that the results are published (or at least made available), independent of whether the findings corroborate the researchers' views or not. Pre-registration also serves to limit a number of questionable research practices such as selective reporting and hypothesizing after results are known (HARKing; see Nosek et al., 2019). 


\section{Supporting organizations in data maintenance}

Loss of data is an increasing risk in a dynamic and high-yield environment. Part of the power commercial publishers have built up is that they control access to valuable information. These include journal articles and books, but also datasets, which are stored digitally. This is a risk in an evolving world where learned societies keep the rights over the journals they publish. Changing publisher entails a risk of losing information. To give one example. Sometime ago, whenever I was action editor I encouraged authors to make data and code available as supplementary materials attached to their articles. This worked well until a learned society changed publisher and had the journal's website transferred to the new publisher. The articles were duly transferred, but the links to supplementary materials no longer worked. Currently, I encourage authors to make their data available via Open Science Framework (https://osf.io/), but this too may be an initiative that at some point comes to an end. To prevent this type of mishaps and possible threats by current providers (which are inherent in the system), it would be good if noncommercial copies were kept of open access journals. Funding agencies have various ways of helping here: by making infrastructure available and/or by supporting initiatives of libraries and learned societies. The costs are likely to be minimal and will make sure that publicly collected information does not vanish when companies disappear or are no longer interested in data maintenance.

\section{Conclusion}

It will be interesting to see how open science evolves. At first sight, it is a no-brainer to make publicly funded research findings freely available to everyone. Ever increasing pay walls are unsustainable and publishers have been pushing their luck in the previous decades. On the other hand, free lunches do not exist either. It is unrealistic for researchers to expect that their manuscripts can be evaluated and published for eternity without someone paying something. Based on my experiences, I think that commercial companies competing against each other are still the best guarantee for good service and innovation (e.g., for manuscript submission and handling). However, for reasons outlined above, these companies must be reined in by people who put the ideals of scientific progress and accessibility first. Otherwise, temptations for easy profit are too large. In that respect, there is no good alternative to learned societies governed by the researchers themselves. Complementary to the role of learned societies, grant funding agencies have the unique power to nudge researchers toward open science practices and to make sure that the findings of the research they support are copied to secure systems immune to the siren call of profit making. 


\section{References}

Baldwin, M. (2018). Scientific autonomy, public accountability, and the rise of "peer review" in the Cold War United States. Isis, 109(3), 538-558.

Brysbaert, M., \& Rastle, K. (2020). Historical and conceptual issues in psychology ( $3^{\text {rd }}$ edition). Pearson Education.

Crawford, W. (2002). 'Free electronic refereed journals: getting past the arc of enthusiasm'. Learned Publishing, 15: 117-123.

Dewsbury, D. A. (1996). History of the Psychonomic Society II: The journal publishing program. Psychonomic Bulletin \& Review, 3(3), 322-338.

Dewsbury, D. A., \& Bolles, R. C. (1995). The founding of the Psychonomic Society. Psychonomic Bulletin \& Review, 2(2), 216-233.

Klein, O., Hardwicke, T. E., Aust, F., Breuer, J., Danielsson, H., Mohr, A. H., ... \& Vazire, S. (2018). A practical guide for transparency in psychological science. Collabra: Psychology, 4(1).

Laakso, M., Welling, P., Bukvova, H., Nyman, L., Björk, B. C., \& Hedlund, T. (2011). 'The development of open access journal publishing from 1993 to 2009'. PloS One, 6: e20961.

McKay, R., \& Coltheart, M. (2017, July 25). 'Breaking the ice with buxom grapefruits: Pratiques de publication and predatory publishing'. Available online at:

http://deevybee.blogspot.com/2017/07/breaking-ice-with-buxom-grapefruits.html.

Munafò, M. R., Nosek, B. A., Bishop, D. V., Button, K. S., Chambers, C. D., Du Sert, N. P., ... \& loannidis, J. P. (2017). A manifesto for reproducible science. Nature Human Behaviour, 1(1), 1-9.

Nosek, B. A., Beck, E. D., Campbell, L., Flake, J. K., Hardwicke, T. E., Mellor, D. T., ... \& Vazire, S. (2019). Preregistration is hard, and worthwhile. Trends in Cognitive Sciences, 23(10), 815-818.

Rooryck, J. (2016). Introducing Glossa. Glossa: A Journal of General Linguistics, 1(1), 1. DOI: http://doi.org/10.5334/gigl.91

Van Calster, B., Wynants, L., Riley, R. D., van Smeden, M., \& Collins, G. S. (2021). Methodology over metrics: Current scientific standards are a disservice to patients and society. Journal of Clinical Epidemiology. DOI:https://doi.org/10.1016/j.jclinepi.2021.05.018.

Vines, T. H., Albert, A. Y., Andrew, R. L., Débarre, F., Bock, D. G., Franklin, M. T., ... Rennison, D. J. (2014). The availability of research data declines rapidly with article age. Current biology, 24(1), 94-97. 